\title{
Role of Neoadjuvant Radio-chemotherapy for the Treatment of High Rectal Cancer
}

\author{
MAXI TREDER ${ }^{1}$, STEFAN JANSSEN ${ }^{1,2}$, NIELS HENRIK HOLLÄNDER ${ }^{3}$, STEVEN E. SCHILD ${ }^{4}$ and DIRK RADES ${ }^{1}$ \\ ${ }^{1}$ Department of Radiation Oncology, University of Lübeck, Lübeck, Germany; \\ ${ }^{2}$ Private Practice of Radiation Oncology, Hannover, Germany; \\ ${ }^{3}$ Department of Oncology and Palliative Units, Zealand University Hospital, Naestved, Denmark; \\ ${ }^{4}$ Department of Radiation Oncology, Mayo Clinic, Scottsdale, AZ, U.S.A.
}

\begin{abstract}
Background/Aim: Controversy exists regarding treatment of high rectal cancer. The role of neoadjuvant radio-chemotherapy was investigated. Patients and Methods: Fifty-four patients receiving neoadjuvant radio-chemotherapy (50.4 Gy \& 2 courses of concurrent chemotherapy) for stage II/III high rectal cancer (10.1-15.0 cm from anal verge) were retrospectively analyzed. Following microscopicallly complete resection of primary tumor and involved lymph nodes in all patients, $\leq 6$ courses of chemotherapy were given. Results: Five-year rates of local control (LC), metastases-free survival (MFS) and overall survival (OS) were 90\%, 79\% and $77 \%$. On multivariate analyses, LC was associated with lower pathological UICC-stage at surgery $(p=0.003)$ and successful downstaging $(p=0.007), M F S$ with higher regression grade $(p=0.014)$ and $O S$ with lower Union for International Cancer Control (UICC)-stage $(p=0.017)$ and downstaging $(p=0.034)$. Grade 3 acute toxicities occurred in 19\% of patients; grade $\geq 3$ late toxicities were not observed. Manageable surgeryrelated complications occurred in 43\%. Conclusion: Neoadjuvant radio-chemotherapy for high rectal cancer was well tolerated and led to promising results. Comparative studies are required to investigate whether it is superior to postoperative chemotherapy alone.
\end{abstract}

In the European Union, the incidence of rectal cancer is about 125,000 per year, i.e. annually 15-25 new cases per 100,000 inhabitants, and is predicted to increase in the future (1). The reported mortality is $4-10$ per 100,000 inhabitants. With respect to the distance from the anal verge, rectal

Correspondence to: Professor Dirk Rades, MD, Department of Radiation Oncology, University of Lübeck, Ratzeburger Allee 160, 23562 Lübeck, Germany. Tel: +49 45150045401, Fax: +49 45150045404, e-mail: rades.dirk@gmx.net

Key Words: High rectal cancer, neoadjuvant radio-chemotherapy, treatment outcomes, toxicities. cancers are classified as low, middle or high. According to the European Society for Medical Oncology (ESMO), low rectal cancers are defined to be located within $5.0 \mathrm{~cm}$ from the anal verge, middle cancers between 5.1 and $10.0 \mathrm{~cm}$, and high cancers between 10.1 and $15.0 \mathrm{~cm}$ (1). Controversy exists regarding the optimal treatment of high rectal cancers. The main question is whether these tumors should be treated like colon cancers (surgery followed by chemotherapy) or rectal cancers (neoadjuvant radiotherapy or radiochemotherapy followed by surgery \pm chemotherapy). Different from the ESMO classification, which was used in two randomized trials $(2,3)$, other definitions of high rectal cancers were used in other trials. In a trial from Sweden, the height of high rectal cancers was defined as $\geq 11 \mathrm{~cm}$, and in a trial from Germany 10.0-16.0 $\mathrm{cm}(4,5)$. The difference regarding the definition of the height of high rectal cancer makes it difficult to compare the results of the available studies. Another difficulty that physicians face when attempting to define the optimal treatment for high rectal cancers, is the lack of trials that focus specifically on high rectal cancers. Due to these difficulties, recommendations of existing guidelines are of questionable utility. For example, the authors of the current ESMO guidelines, state that upper rectal cancers $(>12 \mathrm{~cm}$ from the anal verge) above the peritoneal reflection do not benefit from neoadjuvant radiotherapy or radio-chemotherapy and should be treated like colon cancers. It appears confusing that the authors use $>12 \mathrm{~cm}$ for this statement but define high rectal cancer as $10.1-15 \mathrm{~cm}$ from the anal verge in the same article. Furthermore, the recommendation was not supported by any references and appears, therefore, confusing (1). In the current German guideline, it is stated that rectal cancers of the upper third (defined either as $10.1-15.0 \mathrm{~cm}$ or $12.1-16.0 \mathrm{~cm}$ from the anal verge) should be treated like colon cancers (6). This recommendation was based on the Swedish trial from 2005 and the 6-year results of the Dutch trial from 2007, which did not demonstrate a benefit for addition of neoadjuvant radiotherapy or radio-chemotherapy in patients 
Table I. Grade of regression following radiotherapy or radio-chemotherapy according to Dworak et al. $(9,10)$.

Grade 0: No tumor regression;

Grade 1: Dominant tumor mass with obvious fibrosis and/or vasculopathy;

Grade 2: Dominantly fibrotic changes with few tumor cells or groups;

Grade 3: Very few (difficult to find microscopically) tumor cells in fibrotic tissue;

Grade 4: No tumor cells, only fibrotic mass (total tumor regression or response).

with high rectal cancers $(4,7)$. However, specific data for high rectal cancers from the German trial presented in 2012 and the results of the MRC CR07/NCIC-CTG C016 trial, which both were in favor of neoadjuvant radiotherapy or radio-chemotherapy, were not appropriately considered (3, $8)$. Taking into account the conflicting results from the available trials and the lack of studies focusing on high rectal cancers, the need for additional studies appears important clinically. In the present study, the role of neoadjuvant radiochemotherapy was specifically investigated for high rectal cancers defined according to the ESMO guidelines as 10.1$15.0 \mathrm{~cm}$ from the anal verge.

\section{Patients and Methods}

The data of 54 patients who received neoadjuvant radiochemotherapy for stage II/III high rectal cancer between 2008 and 2017 were retrospectively analyzed. The study was approved by the local ethics committee (University of Lübeck). High rectal cancer was defined as 10.1 to $15.0 \mathrm{~cm}$ from the anal verge on rigid endoscopy according to the ESMO guidelines. Radiotherapy doses were 50.4 Gy in 53 patients and 48.6 Gy in 1 patient. Doses per fraction were $1.8 \mathrm{~Gy}$, given on 5 consecutive days per week. Treatment volumes included the primary tumor and the regional lymph nodes. Neoadjuvant chemotherapy was administered concurrently with radiotherapy in 53 patients and consisted of 5flourouracil (5-FU) or capecitabine (CAPE), which was supplemented by oxaliplatin in three patients. Most patients $(\mathrm{N}=50)$ received 2 concurrent courses of chemotherapy. Of the other 3 patients, 1 patient each had received 1, 4 and 6 courses. After a median of 7 weeks following radio-chemotherapy, surgery was performed, mainly as total mesorectal excision (TME). In all 54 patients, a complete resection of the primary tumor and the involved lymph nodes (R0-resection) was achieved. Following surgery, up to 6 additional courses of chemotherapy were given, mainly with 5-FU or CAPE, either alone or supplemented by oxaliplatin (4 patients) or folinic acid (DeGramont regimen, 6 patients).

In the entire cohort, local control (LC), metastases-free survival (MFS), overall survival (OS) and treatment-related toxicities were evaluated. A total of 9 factors were included in this study and investigated for potential associations with LC, MFS and OS. These factors included age at the start of radiotherapy $(<70 v s . \geq 70$ years, median $=69.5$ years), gender, Karnofsky performance score (70-80 vs. 90-100\%), Union for International Cancer Control (UICC)-stage (stage II vs. III), histologic grading (grade 2 vs. 3), minimum resection margin $(<20 v s . \geq 20 \mathrm{~mm}$, median $=20 \mathrm{~mm})$, grade of regression according to Dworak et al. (grade 0-1 vs. 2 vs. 3-4, Table I) $(9,10)$, pathological UICC-stage at surgery (stage I vs. II $v s$. III), and achievement of downstaging by neoadjuvant radio-chemotherapy defined as decrease by at least one UICC-stage (no vs. yes). Treatment outcomes were referenced from the last day of treatment. Univariate analyses were performed with the Kaplan-Meier method and the log-rank test (11). Those factors that did achieve significance on univariate analyses $(p<0.05)$ were subsequently included in a multivariate analysis performed with the Cox regression method.

In addition to LC, MFS and OS, surgery-related complications as well as acute and late toxicities related to radio-chemotherapy were assessed. The assessment of the toxicities was performed using the Common Terminology Criteria of Adverse Events (CTCAE) version 4.0 (12).

\section{Results}

The 5-year rates of LC, MFS and OS were $90 \%, 79 \%$ and $77 \%$, respectively, for the entire cohort. On univariate analyses, LC was positively associated with a lower pathological UICC-stage at surgery $(p=0.007)$ and achievement of downstaging $(p=0.008)$ (Table II). A positive association was found between MFS and a minimum resection margin of $<20 \mathrm{~mm}(p=0.044)$, a higher grade of regression according to Dworak $(p=0.018)$, a lower pathological UICCstage at surgery $(p=0.009)$ and achievement of downstaging $(p=0.016)$ (Table III). OS was positively associated with a lower histological grading $(p=0.029)$, a lower pathological UICC-stage at surgery $(p=0.009)$ and achievement of downstaging $(p=0.020)$ (Table IV).

If both pathological UICC-stage at surgery and achievement of downstaging were significant on univariate analysis, two multivariate analyses were performed, one including UICC-stage and another one including downstaging, because these were confounding variables. On multivariate analysis of LC, both UICC-stage at surgery ( $p=0.003)$ and achievement of downstaging $(p=0.007)$ were significant. On multivariate analysis of MFS, regression according to Dworak achieved significance $(p=0.014)$, whereas minimum resection margin $(p=0.47)$, UICC-stage at surgery $(p=0.35)$ and achievement of downstaging $(p=0.50)$ were not significant. On multivariate analysis of OS, UICCstage at surgery $(p=0.017)$ and achievement of downstaging $(p=0.034)$ were significant, and histologic grading did not achieve significance $(p=0.09)$. 
Table II. Local control rates following treatment.

\begin{tabular}{|c|c|c|c|c|}
\hline Factor & $\begin{array}{l}\text { Local } \\
\text { control } \\
\text { at } 1 \\
\text { year }(\%)\end{array}$ & $\begin{array}{c}\text { Local } \\
\text { control } \\
\text { at } 3 \\
\text { years }(\%)\end{array}$ & $\begin{array}{l}\text { Local } \\
\text { control } \\
\text { at } 5 \\
\text { years }(\%)\end{array}$ & $p$-Value \\
\hline \multicolumn{5}{|c|}{ Age at start of radiotherapy } \\
\hline$<70$ Years $(\mathrm{N}=27)$ & 100 & 94 & 85 & \\
\hline$\geq 70$ Years $(\mathrm{N}=27)$ & 96 & 96 & 96 & 0.62 \\
\hline \multicolumn{5}{|l|}{ Gender } \\
\hline Female $(\mathrm{N}=25)$ & 100 & 100 & 100 & \\
\hline Male $(\mathrm{N}=29)$ & 96 & 91 & 80 & 0.09 \\
\hline \multicolumn{5}{|c|}{ Karnofsky performance score } \\
\hline $70-80 \%(\mathrm{~N}=11)$ & 89 & 89 & 89 & \\
\hline $90-100 \%(\mathrm{~N}=20)$ & 100 & 100 & 83 & 0.68 \\
\hline \multicolumn{5}{|l|}{$\begin{array}{l}\text { UICC-stage prior } \\
\text { to radiotherapy }\end{array}$} \\
\hline Stage II $(\mathrm{N}=12)$ & 100 & 100 & 100 & \\
\hline Stage III $(\mathrm{N}=42)$ & 97 & 94 & 88 & 0.44 \\
\hline \multicolumn{5}{|l|}{ Histologic grading } \\
\hline Grade $2(\mathrm{~N}=47)$ & 100 & 97 & 90 & \\
\hline Grade $3(N=7)$ & 80 & 80 & 80 & 0.28 \\
\hline \multicolumn{5}{|c|}{ Minimum resection margin } \\
\hline$<20 \mathrm{~mm}(\mathrm{~N}=17)$ & 100 & 90 & 68 & \\
\hline$\geq 20 \mathrm{~mm}(\mathrm{~N}=18)$ & 100 & 100 & 100 & 0.17 \\
\hline \multicolumn{5}{|c|}{ Grade of regression (Dworak) } \\
\hline Grade $0-1(\mathrm{~N}=10)$ & 100 & 75 & not available & \\
\hline Grade $2(N=14)$ & 100 & 100 & 80 & \\
\hline Grade $3-4(\mathrm{~N}=8)$ & 100 & 100 & 100 & 0.39 \\
\hline \multicolumn{5}{|c|}{ UICC-stage at surgery } \\
\hline Stage I $(N=22)$ & 100 & 100 & 100 & \\
\hline Stage II $(\mathrm{N}=17)$ & 100 & 100 & 100 & \\
\hline Stage III $(\mathrm{N}=14)$ & 90 & 77 & 62 & 0.007 \\
\hline \multicolumn{5}{|c|}{ Downstaging achieved } \\
\hline No $(\mathrm{N}=18)$ & 93 & 83 & 69 & \\
\hline Yes $(\mathrm{N}=35)$ & 100 & 100 & 100 & 0.008 \\
\hline Entire cohort & 98 & 95 & 90 & \\
\hline
\end{tabular}

Bold $p$-values: Significant values.

Neoadjuvant radio-chemotherapy was well tolerated. Acute toxicities were reported for 53 patients. Grade 3 toxicities were observed in 10 patients $(19 \%)$. One patient experienced grade 3 diarrhea and grade 3 hematologic toxicity. In addition, 3 patients showed grade 3 diarrhea, 2 patients grade 3 hematologic toxicity, 2 patients grade 3 septicemia, 1 patient grade 3 nausea, 1 patient grade 3 skin toxicity and 1 patient grade 3 dysuria. The distribution of the four most common acute radio-chemotherapy related toxicities are summarized in Table V. Data regarding late toxicities were available for 53 patients. Toxicities were mild to moderate, no grade 3 or higher late toxicity was reported. Late gastrointestinal toxicity was observed in 7 patients ( 3 grade 1, 4 grade 2) (13\%), late genitourinary toxicity in 1 patient (grade 1) (2\%), and other late toxicities in no patient $(0 \%)$. Data regarding complications
Table III. Distant control rates (metastases-free survival) following treatment.

\begin{tabular}{|c|c|c|c|c|}
\hline Factor & $\begin{array}{c}\text { Distant } \\
\text { control } \\
\text { at } 1 \\
\text { year }(\%)\end{array}$ & $\begin{array}{c}\text { Distant } \\
\text { control } \\
\text { at } 3 \\
\text { years }(\%)\end{array}$ & $\begin{array}{c}\text { Distant } \\
\text { control } \\
\text { at } 5 \\
\text { years }(\%)\end{array}$ & $p$-Value \\
\hline$<70$ Years $(\mathrm{N}=27)$ & 96 & 86 & 77 & \\
\hline$\geq 70$ Years $(\mathrm{N}=27)$ & 88 & 83 & 83 & 0.87 \\
\hline \multicolumn{5}{|l|}{ Gender } \\
\hline Female $(\mathrm{N}=25)$ & 92 & 92 & 92 & \\
\hline Male (N=29) & 93 & 79 & 69 & 0.24 \\
\hline \multicolumn{5}{|c|}{ Karnofsky performance score } \\
\hline $70-80 \%(\mathrm{~N}=11)$ & 80 & 68 & 68 & \\
\hline $90-100 \%(\mathrm{~N}=20)$ & 95 & 88 & 73 & 0.42 \\
\hline Stage II (N=12) & 83 & 83 & 83 & \\
\hline Stage III $(\mathrm{N}=42)$ & 95 & 85 & 80 & 0.57 \\
\hline \multicolumn{5}{|l|}{ Histologic grading } \\
\hline Grade $2(N=47)$ & 94 & 85 & 79 & \\
\hline Grade $3(N=7)$ & 80 & 80 & 80 & 0.97 \\
\hline \multicolumn{5}{|c|}{ Minimum resection margin } \\
\hline$<20 \mathrm{~mm}(\mathrm{~N}=17)$ & 94 & 75 & 56 & \\
\hline$\geq 20 \mathrm{~mm}(\mathrm{~N}=18)$ & 100 & 100 & 100 & 0.044 \\
\hline \multicolumn{5}{|c|}{ Grade of regression (Dworak) } \\
\hline Grade $0-1(N=10)$ & 90 & 45 & not available & \\
\hline Grade $2(\mathrm{~N}=14)$ & 100 & 100 & 80 & \\
\hline Grade 3-4 (N=8) & 100 & 100 & 100 & 0.018 \\
\hline \multicolumn{5}{|l|}{ UICC-stage at surgery } \\
\hline Stage $I(N=22)$ & 95 & 95 & 95 & \\
\hline Stage II $(\mathrm{N}=17)$ & 100 & 92 & 92 & \\
\hline Stage III (N=14) & 83 & 60 & 48 & 0.009 \\
\hline \multicolumn{5}{|l|}{ Downstaging achieved } \\
\hline No $(\mathrm{N}=18)$ & 87 & 69 & 57 & \\
\hline Yes $(\mathrm{N}=35)$ & 97 & 93 & 93 & 0.016 \\
\hline Entire cohort & 92 & 84 & 79 & \\
\hline
\end{tabular}

Bold $p$-values: Significant values.

of surgery were available for 51 patients. Twenty-two patients (43\%) experienced at least one complication. Anastomotic leakage was reported In 10 patients (20\%), wound healing problems in 7 patients (14\%), abscess in 4 patients (8\%), ileus in 3 patients $(6 \%)$, bleeding in 2 patients (4\%), high output stoma leading to acute renal failure in 2 patients (4\%) and fistula in 1 patient $(2 \%)$. All complications were manageable, and no complication-related deaths occurred.

\section{Discussion}

Rectal cancer is one of the most common cancer types worldwide (1). Considerable research has been performed to improve the prognoses of these patients including novel systemic treatments, radio-chemotherapy approaches and surgical 
Table IV. Overall survival rates following treatment.

\begin{tabular}{|c|c|c|c|c|}
\hline Factor & $\begin{array}{c}\text { Overall } \\
\text { survival } \\
\text { at } 1 \\
\text { year }(\%)\end{array}$ & $\begin{array}{c}\text { Overall } \\
\text { survival } \\
\text { at } 3 \\
\text { years }(\%)\end{array}$ & $\begin{array}{c}\text { Overall } \\
\text { survival } \\
\text { at } 5 \\
\text { years }(\%)\end{array}$ & $p$-Value \\
\hline \multicolumn{5}{|c|}{ Age at start of radiotherapy } \\
\hline$<70$ Years $(\mathrm{N}=27)$ & 100 & 93 & 93 & \\
\hline$\geq 70$ Years $(\mathrm{N}=27)$ & 92 & 81 & 63 & 0.22 \\
\hline \multicolumn{5}{|l|}{ Gender } \\
\hline Female $(\mathrm{N}=25)$ & 96 & 96 & 78 & \\
\hline Male $(\mathrm{N}=29)$ & 97 & 78 & 78 & 0.39 \\
\hline \multicolumn{5}{|c|}{ Karnofsky performance score } \\
\hline $70-80 \%(\mathrm{~N}=11)$ & 82 & 68 & 68 & \\
\hline $90-100 \%(\mathrm{~N}=20)$ & 100 & 90 & 72 & 0.36 \\
\hline \multicolumn{5}{|l|}{ UICC-stage prior } \\
\hline \multicolumn{5}{|l|}{ to radiotherapy } \\
\hline Stage II $(\mathrm{N}=12)$ & 83 & 83 & 56 & \\
\hline Stage III (N=42) & 100 & 89 & 82 & 0.16 \\
\hline \multicolumn{5}{|l|}{ Histologic grading } \\
\hline Grade $2(\mathrm{~N}=47)$ & 98 & 94 & 83 & \\
\hline Grade $3(\mathrm{~N}=7)$ & 83 & 50 & 50 & 0.029 \\
\hline \multicolumn{5}{|c|}{ Minimum resection margin } \\
\hline$<20 \mathrm{~mm}(\mathrm{~N}=17)$ & 94 & 71 & 71 & \\
\hline$\geq 20 \mathrm{~mm}(\mathrm{~N}=18)$ & 100 & 100 & 100 & 0.08 \\
\hline \multicolumn{5}{|c|}{ Grade of regression (Dworak) } \\
\hline Grade $0-1(\mathrm{~N}=10)$ & 90 & 60 & not available & \\
\hline Grade $2(\mathrm{~N}=14)$ & 100 & 100 & 75 & \\
\hline Grade $3-4(\mathrm{~N}=8)$ & 100 & 100 & 100 & 0.14 \\
\hline \multicolumn{5}{|c|}{ UICC-stage at surgery } \\
\hline Stage I $(\mathrm{N}=22)$ & 100 & 100 & 90 & \\
\hline Stage II (N=17) & 100 & 89 & 89 & \\
\hline Stage III $(\mathrm{N}=14)$ & 86 & 63 & 42 & 0.009 \\
\hline \multicolumn{5}{|c|}{ Downstaging achieved } \\
\hline No $(\mathrm{N}=18)$ & 89 & 69 & 51 & \\
\hline Yes $(\mathrm{N}=35)$ & 100 & 95 & 89 & 0.020 \\
\hline Entire cohort & 96 & 87 & 77 & \\
\hline
\end{tabular}

Bold $p$-values: Significant values.

techniques (13-20). The identification of prognostic factors and personalized treatment decisions can contribute to improved outcomes $(21,22)$. Personalization of the treatment of rectal cancer should also consider the location of the tumor. Particularly high rectal cancers, mostly defined as $10.1-15-0 \mathrm{~cm}$ from the anal verge, should be considered specifically. An important question is whether these tumors should be treated as rectal cancers including neoadjuvant radiotherapy or radio-chemotherapy, or whether neoadjuvant treatment can be omitted like in the treatment of colon (sigmoid) cancer. The results from randomized trials are conflicting with respect to the upper third of the rectum. In the Swedish trial of Folkesson et al., 454 patients received surgery alone and 454 patients received surgery plus upfront radiotherapy with $5 \times 5 \mathrm{~Gy}$ (4). Of these patients, 110 and $133 \mathrm{had}$ high rectal cancer ( $\geq 11 \mathrm{~cm}$ from the anal verge). The local recurrence rates in these patients were $12 \%$ and $8 \%$, respectively $(p=0.3)$. In the Dutch trial of 1,748 eligible patients (533 patients with high rectal cancer, i.e. $10.1-15-0 \mathrm{~cm}$ from the anal verge) that also compared surgery alone to $5 \times 5$ Gy followed by surgery, the 2-year local recurrence rates were $3.8 \%$ and $1.3 \%$ $(p=0.17)$ in those patients with high rectal cancer (2). In 2007, the 5-year results of the Dutch trial (median follow-up=6 years) were published (7). The 5-year local recurrence rates of the patients with high rectal cancer were $6.2 \%$ after surgery alone and $3.7 \%$ after $5 \times 5$ Gy followed by surgery $(p=0.12)$. In 2011 , the 10-year results of this trial were presented (median followup=12 years) (23). For all patients, the positive effect of neoadjuvant radiotherapy on local control became stronger with increased distance from the anal verge $(p=0.03)$. However, when analyzing only those patients with a negative circumferential resection margin, the difference was no longer significant $(p=0.62)$.

Two other trials found that the addition of neoadjuvant radiotherapy or radio-chemotherapy was favorable $(3,8)$. The results of the MRC CR07 trial were published in 2009 (3). Of 1,350 patients enrolled, 674 patients were allocated to preoperative radiotherapy with $5 \times 5 \mathrm{~Gy}$, and 676 patients to receive surgery alone (vast majority of these patients) or, in case of involvement of the circumferential resection margin $(\leq 1 \mathrm{~mm})$, surgery followed by radio-chemotherapy $(25 \times 1.8 \mathrm{~Gy}$ plus concurrent $5-\mathrm{FU})$. In the group of patients with high rectal cancer defined as $10.1-15.0 \mathrm{~cm}$ form the anal verge $(\mathrm{N}=207), 3$-year local recurrence rates were $1.2 \%$ in patients receiving preoperative radiotherapy $v s .6 .2 \%$ in the other group [hazard ratio $(\mathrm{HR})=0.16 ; 95 \%$-confidence interval $0.07-0.47, p<0.05]$. In the update analyses of the German trial, in patients with high rectal cancer $(10.0-16.0 \mathrm{~cm}$ from the anal verge), 5-year local recurrence rates were $2.5 \%$ in those 83 patients receiving preoperative radiotherapy $v s$. $10.4 \%$ in those 45 patients receiving neither preoperative nor postoperative radio-chemotherapy ( $p$-value not stated) (8). The 10-year local recurrence rates were $4.3 \%$ and $10.4 \%$, respectively ( $p$-value not stated).

Because of the conflicting results of the randomized trials with respect to the value of neoadjuvant radiotherapy or radio-chemotherapy and the lack of studies focusing particularly on the treatment of high rectal cancer, additional studies for this group of patients are required. In the present study, we have evaluated the role of neoadjuvant long-course radiotherapy $(28 \times 1.8 \mathrm{~Gy})$ plus concurrent chemotherapy in patients with stage II/III high rectal cancer $(10.0-15.0 \mathrm{~cm}$ from the anal verge). The outcomes in terms of LC (90\% at 5 years), MFS (79\% at 5 years) and OS (77\% at 5 years) were promising, particularly when taking into account that $78 \%$ of the patients had stage III disease and no one had stage I disease. In the 5-year analyses of the Dutch trial including all 861 eligible patients, the LC rates were $94 \%$ in the radiotherapy + surgery group and $89 \%$ in the surgery alone group, the distant control rates $74 \%$ and $72 \%$, and the OS 
Table V. Distribution of common acute toxicities, i.e. diarhea, dysuria, skin toxicity and hematologic toxicity. Grade 4 or 5 toxicities were not observed.

\begin{tabular}{lcccc}
\hline Acute toxicity & $\begin{array}{c}\text { Grade 0 } \\
\text { N patients (\%) }\end{array}$ & $\begin{array}{c}\text { Grade 1 } \\
\text { N patients (\%) }\end{array}$ & $\begin{array}{c}\text { Grade 2 } \\
\text { N patients (\%) }\end{array}$ & $\begin{array}{c}\text { Grade 3 } \\
\text { N patients (\%) }\end{array}$ \\
\hline Diarrhea (reported=52, unknown=2) & $18(35)$ & $17(33)$ & $13(25)$ & $4(8)$ \\
Dysuria (reported=52, unknown=2) & $35(67)$ & $13(25)$ & $3(6)$ & $1(2)$ \\
Skin toxicity (reported=51, unknown=3) & $29(57)$ & $10(20)$ & $11(22)$ & $1(2)$ \\
Hematologic toxicity (reported=53, unknown=1) & $32(60)$ & $10(19)$ & $8(15)$ & $3(6)$ \\
\hline
\end{tabular}

rates $64 \%$ and $64 \%(7)$. Five-year LC rates for high rectal cancers were $96 \%$ and $94 \%$. However, in contrast to our present study, $60 \%$ of the patients in the Dutch trial had stage I $(31 \%)$ or stage II $(29 \%)$ disease $(2,7)$. In patients with stage III disease, 5-year LC rates were $89 \%$ in the radiotherapy + surgery group and $79 \%$ in the surgery alone group. In the German trial, the 5-year rates of LC, MFS and OS in those patients receiving neoadjuvant radio-chemotherapy followed by surgery and additional chemotherapy were $94 \%, 64 \%$ and $76 \%$, respectively (5). However, the proportion (54\%) of patients with more advanced tumors, i.e. stage III disease, was also lower than in the present study $(78 \%)$. The third trial stating 5-year results was the MRC CR07 trial (3). In the entire cohort, 5-year LC rates were $95 \%$ in those patients receiving preoperative radiotherapy and $88 \%$ in the other group. 5-year OS rates were $70 \%$ and $68 \%$, respectively. In this trial, $59 \%$ and $56 \%$ of the patients had stage I or II disease. The 3-year LC rates in the preoperative radiotherapy $v s$. the other group were $98 \%$ vs. $97 \%$ for stage I disease, $98 \%$ vs. $94 \%$ for stage II disease and $93 \%$ vs. $85 \%$ for stage III disease. In all patients with high rectal cancer, the 3-year LC rates were $99 \%$ and $94 \%$.

Since all randomized trials included a much greater proportion of lower UICC-stage tumors than our present study, the results are difficult to compare. However, despite the greater proportion of stage III tumors in our present study, the MFS- and OS-rates appeared similar to those of the previous trials. Results of LC appeared worse than in patients with high rectal cancer from the previous trials, which was most likely due to the more advanced tumors in our study.

When interpreting the results of our study, one has to be aware of its limitations, particularly the retrospective design and the comparably small sample size. This study may also be criticized, because 9 patients $(17 \%)$ had not received postoperative chemotherapy. However, this aspect can be considered less important, since a randomized trial comparing postoperative 5-FU-based chemotherapy after preoperative radiotherapy or radio-chemotherapy and surgery did not demonstrate a significant benefit of the additional postoperative chemotherapy with respect to 5-year OS $(79 \%$ vs. 80\%, $p=0.73)$ MFS (61\% vs. 65\%, $p=0.39)$ and LC $(92 \%$ $v s .92 \%$ ) (14). In addition, in the SCOT trial of 6,088 patients with stage II or III colorectal cancer that compared 3 vs. 6 months of adjuvant oxaliplatin-fluoropyrimidine treatment, the 3-month regimen was not inferior but associated with better tolerance and quality of life (24).

One argument used against the addition of neoadjuvant radiotherapy or radio-chemotherapy for high rectal cancers, is the potential higher risk of acute and late toxicities and perioperative complications due to the inclusion of greater volumes of the colon and the small bowels in the radiation fields when compared to cancers of the lower or middle rectum. In the current study, the neoadjuvant radiochemotherapy itself was well tolerated. Grade 3 acute toxicities were observed in $19 \%$ of the patients. This rate was lower than the $27 \%$ of grade 3 or 4 toxicities observed in the neoadjuvant treatment group of the German trial, which included mainly patients with low or middle rectal cancer (5). Grade 3 or 4 hematological toxicity of the present study and the German trial were the same $(6 \%)$, whereas diarrhea $(8 \%$ vs. $12 \%)$ and skin toxicity (2\% vs. $11 \%)$ were less frequent in our study. In the German trial, $14 \%$ of patients experienced a grade 3 or 4 late toxicity $v s$. no patients in the present study (5). In the other three trials, acute and late toxicities related to neoadjuvant radiotherapy were not clearly stated (2-4). In an update report of the Dutch trial, it was mentioned that 2 patients $(0.6 \%)$ died due to radiotherapy-related complications (23). In contrast to radio-chemotherapy related toxicities, complications during or following surgery were more common in the present study than in the German trial (5). The overall rates of complications were $43 \%$ in our study and $36 \%$ in the German trial. The rates of anastomotic leakage of any grade were $20 \%$ and $11 \%$, respectively. Wound-healing complications occurred in $14 \%$ and $10 \%$, bleeding in $4 \%$ and $3 \%$ of the patients, respectively. The quality of surgery in the present study was excellent; a microscopically complete resection was achieved in all patients, even with wide minimum resection margins (median $20 \mathrm{~mm}$ ). For example, in the MRC CR07 trial, a microscopically complete resection 
was not achieved in $12 \%$ of the patients (3). Thus, the higher rate of perioperative complications was likely associated with the height of the tumors. In the German trial, $12 \%$ of the patients had high rectal cancer $(>10 \mathrm{~cm})$ compared to $100 \%$ in the present study. The comparably high rate of complications may be an argument to omit neoadjuvant radiotherapy or radio-chemotherapy. On the other hand, neoadjuvant treatment led to a downstaging by at least one UICC stage in 35 of 53 patients (66\%). Moreover, successful downstaging was an independent predictor of improved LC and OS. This result demonstrates the importance of downstaging. However, the question may be raised whether the impact of successful downstaging on the patients' prognoses can be used as an argument in favor of neoadjuvant treatment or is just a surrogate marker, i.e. good response translated into better LC and OS.

In summary, neoadjuvant radio-chemotherapy for high rectal cancer was well tolerated and led to promising results, particularly when taking into account that $78 \%$ of the patients had stage III disease. Perioperative complications were more frequent than in a previous trial, which included mainly patients with low or middle rectal cancer. Successful downstaging with neoadjuvant radio-chemotherapy was achieved in about two thirds of the patients and associated with significantly better LC and OS. When taking into account the results from the available trials and the present study, it becomes obvious that comparative studies with $v s$. without neoadjuvant radiotherapy or radio-chemotherapy are required to properly define the optimal treatment for patients with high rectal cancers.

\section{Acknowledgements}

The study was part of the project InnoCan, which is funded by Interreg Deutschland-Danmark with funds from the European Regional Development Fund.

\section{Conflicts of Interest}

On behalf of all Authors, the corresponding Author states that there is no conflict of interest related to this study.

\section{References}

1 Glynne-Jones R, Wyrwicz L, Tiret E, Brown G, Rödel C, Cervantes A and Arnold D; ESMO Guidelines Committee: Rectal cancer: ESMO Clinical Practice Guidelines for diagnosis, treatment and follow-up. Ann Oncol 28(Suppl 4): iv22-iv40, 2017.

2 Kapiteijn E, Marijnen CA, Nagtegaal ID, Putter H, Steup WH, Wiggers T, Rutten HJ, Pahlman L, Glimelius B, van Krieken JH, Leer JW and van de Velde CJ; Dutch Colorectal Cancer Group: Preoperative radiotherapy combined with total mesorectal excision for resectable rectal cancer. N Engl J Med 345: 638646, 2001.
3 Sebag-Montefiore D, Stephens RJ, Steele R, Monson J, Grieve R, Khanna S, Quirke P, Couture J, de Metz C, Myint AS, Bessell E, Griffiths G, Thompson LC and Parmar M: Preoperative radiotherapy versus selective postoperative chemoradiotherapy in patients with rectal cancer (MRC CR07 and NCIC-CTG C016): a multicentre, randomised trial. Lancet 373: 811-820, 2009.

4 Folkesson J, Birgisson H, Pahlman L, Cedermark B, Glimelius B and Gunnarsson U: Swedish Rectal Cancer Trial: long lasting benefits from radiotherapy on survival and local recurrence rate. J Clin Oncol 23: 5644-5650, 2005.

5 Sauer R, Becker H, Hohenberger W, Rödel C, Wittekind C, Fietkau R, Martus P, Tschmelitsch J, Hager E, Hess CF, Karstens JH, Liersch T, Schmidberger H and Raab R; German Rectal Cancer Study Group: Preoperative versus postoperative chemoradiotherapy for rectal cancer. N Engl J Med 351: 17311740, 2004.

6 Leitlinienprogramm Onkologie (Deutsche Krebsgesellschaft, Deutsche Krebshilfe, AWMF): S3-Leitlinie Kolorektales Karzinom, Langversion 2.0, 2017, AWMF Registrierungsnummer: 021/007OL, http://www.leitlinienprogramm-onkologie.de/leitlinien/ kolorektales-karzinom/

7 Peeters KC, Marijnen CA, Nagtegaal ID, Kranenbarg EK, Putter H, Wiggers T, Rutten H, Pahlman L, Glimelius B, Leer JW and van de Velde CJ; Dutch Colorectal Cancer Group: The TME trial after a median follow-up of 6 years: increased local control but no survival benefit in irradiated patients with resectable rectal carcinoma. Ann Surg 246: 693-701, 2007.

8 Sauer R, Liersch T, Merkel S, Fietkau R, Hohenberger W, Hess C, Becker H, Raab HR, Villanueva MT, Witzigmann H, Wittekind C, Beissbarth T and Rödel C: Preoperative versus postoperative chemoradiotherapy for locally advanced rectal cancer: results of the German CAO/ARO/AIO-94 randomized phase III trial after a median follow-up of 11 years. J Clin Oncol 30: 1926-1933, 2012.

9 Dworak O, Keilholz L and Hoffmann A: Pathological features of rectal cancer after preoperative radiochemotherapy. Int $\mathrm{J}$ Colorect Dis 12: 19-23, 1997.

10 Mihaylova I, Parvanova V, Velikova C, Kurteva G and Ivanova D: Degree of tumor regression after preoperative chemoradiotherapy in locally advanced rectal cancer-Preliminary results. Rep Pract Oncol Radiother 16: 237-242, 2011.

11 Kaplan EL and Meier P: Non parametric estimation from incomplete observations. J Am Stat Assoc 53: 457-481, 1958.

12 National Institutes of Health/National Cancer Institute: Common Terminology Criteria for Adverse Events (CTCAE) version 4.0. U.S. Department of Health and Human Services, National Institutes of Health, National Cancer Institute, 2009.

13 Ide S, Toiyama Y, Okugawa Y, Oki S, Yasuda H, Fujikawa H, Yoshiyama S, Hiro J, Kobayashi M, Ohi M, Araki T and Kusunoki M: Clinical significance of C-reactive protein-toalbumin ratio with rectal cancer patient undergoing chemoradiotherapy followed by surgery. Anticancer Res 37: 5797-5804, 2017.

14 Breugom AJ, van Gijn W, Muller EW, Berglund A, van den Broek CB, Fokstuen T, Gelderblom H, Kapiteijn E, Leer JW, Marijnen CA, Martijn H, Meershoek-Klein Kranenbarg E, Nagtegaal ID, Påhlman L, Punt CJ, Putter H, Roodvoets AG, Rutten HJ, Steup WH, Glimelius B and van de Velde CJ; Cooperative Investigators of Dutch Colorectal Cancer Group and 
Nordic Gastrointestinal Tumour Adjuvant Therapy Group: Adjuvant chemotherapy for rectal cancer patients treated with preoperative (chemo)radiotherapy and total mesorectal excision: a Dutch Colorectal Cancer Group (DCCG) randomized phase III trial. Ann Oncol 26: 696-701, 2015.

15 Yamamoto S, Kanai T, Osumi K, Yo K, Takano K, Tsutsui M, Nakanishi R, Yoshikawa Y, Kaneko $\mathrm{Y}$ and Nakagawa M: Anastomotic leakage using linear stapling device with preattached bioabsorbable polyglycolic acid felt after laparoscopic anterior resection. Anticancer Res 37: 7083-7086, 2017.

16 Nonaka T, Fukuda A, Maekawa K, Nagayoshi S, Tokunaga T, Takatsuki M, Kitajima T, Taniguchi K and Fujioka H: Clinical and oncological outcomes of laparoscopic lateral pelvic lymph node dissection in advanced lower rectal cancer: Singleinstitution experience. Anticancer Res 37: 5095-5100, 2017.

17 Quirke P, Steele R, Monson J, Grieve R, Khanna S, Couture J, O'Callaghan C, Myint AS, Bessell E, Thompson LC, Parmar M, Stephens RJ and Sebag-Montefiore D; MRC CR07/NCIC-CTG CO16 Trial Investigators; NCRI Colorectal Cancer Study Group: Effect of the plane of surgery achieved on local recurrence in patients with operable rectal cancer: a prospective study using data from the MRC CR07 and NCIC-CTG CO16 randomised clinical trial. Lancet 373: 821-828, 2009.

18 Eisterer W, Piringer G, DE Vries A, Öfner D, Greil R, Tschmelitsch J, Samonigg H, Sölkner L, Gnant M and Thaler J; Austrian Breast and Colorectal Cancer Study Group: Neoadjuvant chemotherapy with capecitabine, oxaliplatin and bevacizumab followed by concomitant chemoradiation and surgical resection in locally advanced rectal cancer with high risk of recurrence - a phase II study. Anticancer Res 37: 26832691, 2017.

19 Rödel C, Graeven U, Fietkau R, Hohenberger W, Hothorn T, Arnold D, Hofheinz RD, Ghadimi M, Wolff HA, LangWelzenbach M, Raab HR, Wittekind C, Ströbel P, Staib L, Wilhelm M, Grabenbauer GG, Hoffmanns H, Lindemann F, Schlenska-Lange A, Folprecht G, Sauer R and Liersch T; German Rectal Cancer Study Group: Oxaliplatin added to fluorouracil-based preoperative chemoradiotherapy and postoperative chemotherapy of locally advanced rectal cancer (the German CAO/ARO/AIO-04 study): final results of the multicentre, open-label, randomised, phase 3 trial. Lancet Oncol 16: 979-989, 2015.
20 Lee IH, Hwang S, Lee SJ, Kang BW, Baek D, Kim HJ, Park SY, Park JS, Choi GS, Kim JC, Cho SH and Kim JG: Systemic inflammatory response after preoperative chemoradiotherapy can affect oncologic Outcomes in locally advanced rectal cancer. Anticancer Res 37: 1459-1465, 2017.

21 Rades D, Kuhn H, Schultze J, Homann N, Brandenburg B, Schulte R, Krull A, Schild SE and Dunst J: Prognostic factors affecting locally recurrent rectal cancer and clinical significance of hemoglobin. Int J Radiat Oncol Biol Phys 70: 1087-1093, 2008.

22 Schmoll HJ, Van Cutsem E, Stein A, Valentini V, Glimelius B, Haustermans K, Nordlinger B, van de Velde CJ, Balmana J, Regula J, Nagtegaal ID, Beets-Tan RG, Arnold D, Ciardiello F, Hoff P, Kerr D, Köhne CH, Labianca R, Price T, Scheithauer W, Sobrero A, Tabernero J, Aderka D, Barroso S, Bodoky G, Douillard JY, El Ghazaly H, Gallardo J, Garin A, Glynne-Jones R, Jordan K, Meshcheryakov A, Papamichail D, Pfeiffer P, Souglakos I, Turhal S and Cervantes A: ESMO Consensus Guidelines for management of patients with colon and rectal cancer. A personalized approach to clinical decision making. Ann Oncol 23: 2479-2516, 2012.

23 van Gijn W, Marijnen CA, Nagtegaal ID, Kranenbarg EM, Putter H, Wiggers T, Rutten HJ, Påhlman L, Glimelius B and van de Velde CJ; Dutch Colorectal Cancer Group: Preoperative radiotherapy combined with total mesorectal excision for resectable rectal cancer: 12-year follow-up of the multicentre, randomised controlled TME trial. Lancet Oncol 12: 575-582, 2011.

24 Iveson TJ, Kerr RS, Saunders MP, Cassidy J, Hollander NH, Tabernero J, Haydon A, Glimelius B, Harkin A, Allan K, McQueen J, Scudder C, Boyd KA, Briggs A, Waterston A, Medley L, Wilson C, Ellis R, Essapen S, Dhadda AS, Harrison M, Falk S, Raouf S, Rees C, Olesen RK, Propper D, Bridgewater J, Azzabi A, Farrugia D, Webb A, Cunningham D, Hickish T, Weaver A, Gollins S, Wasan HS and Paul J: 3 versus 6 months of adjuvant oxaliplatin-fluoropyrimidine combination therapy for colorectal cancer (SCOT): an international, randomised, phase 3, non-inferiority trial. Lancet Oncol 19: 562-578, 2018.

Received July 27, 2018

Revised August 6, 2018

Accepted August 7, 2018 